\title{
A Física Nuclear sob uma perspectiva interdisciplinar
}

The Nuclear Physics in an interdisciplinary perspective

\author{
A.R. Pires ${ }^{1}$; J.E. Andrade ${ }^{2}$; J.M. Dantas ${ }^{3}$ \\ ${ }^{1}$ Faculdade de Física/Instituto de Ciências Exatas/Programa Nacional de Mestrado Profisional em Ensino de Física, \\ Universidade Federal do Sul e Sudeste do Pará, 68507-590, Marabá - Pará, Brasil \\ ${ }^{2}$ Faculdade de Engenharia Mecânica/Instituto de Geociências e Engenharias, \\ Universidade Federal do Sul e Sudeste do Pará \\ aculdade de Computação e Engenharia Elétrica/Instituto de Geociências e Engenharias, Universidade Federal do \\ Sul e Sudeste do Pará, 68507-590, Marabá - Pará, Brasil \\ *cientistadriano@yahoo.com.br \\ (Recebido em 30 de agosto de 2016; aceito em 11 de dezembro de 2016)
}

\begin{abstract}
A Física Nuclear é um campo da Ciência e Tecnologia extremamente vasto de estudos e pesquisas, e que ao longo da história da humanidade permitiu ao homem explicar fenômenos naturais, como o decaimento radioativo, descobertas de partículas como os neutrinos, construção de bombas, reatores, aceleradores de partícula, instrumentos para medicina, satélites, agricultura etc. Nesse sentido, o objetivo desse trabalho é de direcionar os docentes para o desenvolvimento em parceria de uma proposta interdisciplinar promovendo interação entre as diferentes abordagens feitas pelas disciplinas de História e Física acerca do tema Física nuclear, assim como compreender a ligação entre elas na busca da construção de informações relevantes ao desenvolvimento de uma aprendizagem contextualizada e significativa considerando aspectos históricos e científicos. A metodologia desenvolvida se deu a partir de um questionário, aplicado a 30 alunos do $3^{\circ}$ ano do ensino médio no Colégio Estadual Anunciada Chaves, sendo este situado no município de Goianésia do Pará, o estudo foi desenvolvido a partir de uma pesquisa quanti - qualitativa exploratória a qual constitui - se no método mais adequado para obter resultados importantes sobre os autores delimitados como a falta de conhecimento acerca do tema e a incoerência do processo educativo que ainda preconiza a fragmentação e o isolamento de disciplinas reiterando o objetivo e permitindo-nos ampliar esse estudo.

Palavras-chave: Física, História, Interdisciplinaridade
\end{abstract}

The nuclear physics is a field of the Science and Technology extremely vast of the study and researched, and that over the history of humanity allowed the man to explain natural phenomena, like radioactive decay, discoveries particle as neutrinos, bomb construction, reactors, particle accelerators, medicine tools, satellite, agriculture, etc. In this sense, the objective this work is to direct the professor for the development in partnership of an interdisciplinary proposal promoting interaction between different approaches doing for history and physics subject about the nuclear physics topic, as well as understand the connection between them in the search of construction of information relevant to the development of a contextualized and meaning learning considers history and science aspects. The develop methodology was given from one questionnaire, applied to 30 students of the $3^{\text {rd }}$ year in the high school in the Colégio Estadual Anunciara Chaves, which is located in Goianésia of Pará, the study was developed from of an research quanti - qualitative exploratory which constitute - if the method more adequate for get results import about the authors delimited like the lack of knowledge on the subject and the incoherence of education process that yet advocates the fragmentation and the insolation of discipline reinterring the objective and allowing us the expand in this study.

Keyword: Physics, History, Interdisciplinary. 


\section{INTRODUÇÃO}

Em 1945 a humanidade sentiu na pele a mais cruel aplicação prática da Física de todos os tempos, as explosões das bombas atômicas, tal abordagem histórica, se faz presente até hoje em livros didáticos, aulas de História, geografia e outras disciplinas, nesse sentido o campo da Física chamado Física nuclear é apresentado para alunos e sociedade como sinônimo de bombas, destruição e ameaça que foi e que continua sendo para humanidade.

O apanhado histórico da Física Nuclear na escola reforça uma proposta curricular acrítica e incoerente do ponto de vista científico, uma vez que há uma visão restrita do tema na forma como é apresentado e discutido por professores e alunos. Numa aula de História cujo conteúdo a ser desenvolvido é a Segunda Guerra Mundial, por exemplo, a Física nuclear aparece de forma inevitável, cabendo ao professor saber conduzir significativamente a temática numa abordagem ampla e interdisciplinar, o mesmo tipo de articulação poderia ser realizado para assuntos como Guerra Fria, conflitos no Oriente Médio, entre outros, presentes também nas aulas de disciplinas como Geografia e Sociologia.

A Física nuclear, não é apenas a Bomba A ou a Bomba $\mathrm{H}$, e sim, a construção histórica de conhecimentos que vem sendo desenvolvido desde o século XIX até hoje, no campo de estudos do núcleo atômico e suas propriedades. A descoberta da radioatividade por Henri Becquerel em 1896, do Nêutron por Chadwick em 1932, da radioatividade artificial, em 1934, pelo casal Irene Curie e Pierre Joliot e o desenvolvimento nos anos 50 e 60 dos aceleradores de partículas de íons pesados de altas energias e da instrumentação nuclear, são apenas alguns dos exemplos de estudos e pesquisas desenvolvidas por essa área tão importante e vasta de conhecimento. "Conhecimentos acerca do átomo e suas implicações tem um impacto profundo sobre a sociedade humana" [1].

Ao considerar que a temática requer uma perspectiva mais adequada e abrangente, professores de História e Física devem articular uma proposta de ensino que apresente aos alunos informações necessárias à compreensão do que realmente é a Física Nuclear, sua importância histórica e contribuição para o avanço da ciência e tecnologia. Nesse sentido, os professores teriam uma excelente oportunidade de desenvolver em parceria um trabalho interdisciplinar, contemplando aspectos políticos, bélicos e científicos, que proporcionariam aos alunos, refletir sobre o tema numa visão mais crítica e contextualizada.

Apesar das diferenças, seja no campo das informações ou das especificidades, História e Física, têm muita coisa em comum, existem momentos em sala de aula que uma depende da outra para garantir a explicação de um conteúdo, dentro das complexidades de cada uma. $\mathrm{O}$ professor de Física, por exemplo, ao discutir sobre fissão nuclear não pode deixar de falar da experiência realizada pelo químico alemão Otto Hahn, em 1938 ou do projeto Manhattan e o desenvolvimento das primeiras bombas atômicas e o fim da Segunda Guerra Mundial, assunto apresentado nas aulas de História e que dependendo da dimensão das informações poderia retomar o debate acerca do tema gerador, valendo ressaltar que para uma ou outra disciplina é necessário fazer abordagens de pontos positivos, como a análise dos mecanismos dos reatores nucleares e as transformações de energia.

A História e a Física apresentam campos necessariamente interdisciplinares, em decorrência disso alguns autores ressaltam a necessidade de um debate acerca das diversas concepções de História, da natureza da ciência e da tecnologia e suas relações com o ensino. "Isso resulta uma polifonia que implica atritos e aproximações entre as diversas visões de História e de ciência [...]" [2].

Ao longo dos anos mudanças significativas marcaram a relação de História e Ciência. A firmação da ciência e tecnologia como status de conhecimento superior a outras formas de conhecimento, os avanços em pesquisa, os altos investimentos (Big Science) e outros fatores proporcionaram o distanciamento da História da Ciência e Tecnologia da própria História. 
"[...] Sob impacto do conhecido trabalho de Thomas Kuhn, $\boldsymbol{A}$ estrutura das revoluções científicas, aliado a pesquisas semelhantes levadas a cabo por outros pesquisadores, foi rejeitada a premissa, até então corrente de que a Ciência e a Tecnologia poderia ser estudada independentemente do contexto histórico mais amplo - social, político, econômico, cultural, religioso" [2].

Essa analise estabelece a necessidade da integração entre a História da Ciência e a História em geral, permitindo a compreensão de informações científicas, numa perspectiva educacional de construção de conhecimento, que seja contemplada pelos Parâmetros Curriculares Nacionais para o Ensino Médio (PCNs) [3]:

\begin{abstract}
"A nova identidade atribuída ao ensino médio define-o [...] como uma etapa conclusiva da educação básica para a população estudantil. $\mathrm{O}$ objetivo é o de preparar o educando para a vida, para o exercício da cidadania, para sua inserção qualificada no mundo do trabalho, e capacitá-lo para o aprendizado permanente e autônomo, não se restringindo a prepará-lo para outra etapa escolar ou para o exercício profissional. Dessa forma, o ensino de História, articulando-se com o das outras disciplinas, busca oferecer aos alunos possibilidades de desenvolver competências que os instrumentalizem a refletir sobre si mesmos, a se inserir e a participar ativa e criticamente no mundo social, cultural e do trabalho" [3].
\end{abstract}

Nesse sentido, deve haver uma articulação entre História e outras disciplinas diante de uma perspectiva de ensino que garanta aos alunos o desenvolvimento de competências, que possibilitem reflexão e participação ativa no mundo. Essa visão nos permite compreender que a aprendizagem só pode de fato ser alcançada à medida que se busca conhecer as diferentes abordagens dos diversos campos de conhecimento que um único conteúdo pode apresentar, assim como as relações entre eles. Dessa forma, os parâmetros curriculares nacionais apresentam a interdisciplinaridade como ferramenta indispensável ao processo de ensino aprendizagem. Para os PCNs,

"A interdisciplinaridade supõe um eixo integrador, que pode ser o objeto de conhecimento, um projeto de investigação, um plano de intervenção. Nesse sentido, ela deve partir da necessidade sentida pelas escolas, professores e alunos de explicar, compreender, intervir, mudar, prever, algo que desafia uma disciplina isolada e atrai a atenção de mais de um olhar, talvez vários" [3].

A interdisciplinaridade constitui um mecanismo de integração necessário, permitindo ao professor reconsiderar sua prática pedagógica e investigar estratégias desenvolvidas em sala de um tema que exige a discussão de diferentes disciplinas, isto é, fundamenta-se na relação de interação entre os sujeitos educativos e a ligação entre as diferentes áreas de conhecimento. Nesse sentido, Japiassú [4]: "[...] Caracteriza a interdisciplinaridade pela presença de uma axiomática comum a um grupo de disciplinas conexas e definida no nível hierárquico imediatamente superior, o que introduz a noção de finalidade" [4].

A Física é uma ciência experimental, o desenvolvimento de estudos acerca da evolução do núcleo atômico e suas propriedades, incorpora descobertas empíricas importantes realizadas por inúmeros pesquisadores ao longo dos anos, assim como, conceitos de relatividade, mecânica quântica e física estatística. Apesar do grau de complexidade apresentado em alguns momentos pela temática, os livros didáticos de Física do ensino médio são ótimas ferramentas de 
fundamentação teórica para professores e alunos. A maioria deles apresenta apanhados históricos importantes que estabelecem complementos necessários à aprendizagem, desde registros bibliográficos até momentos relevantes de implicação para Física e História, numa abordagem contextualizada, fatos estes nem sempre conectados a disciplina de História. Segundo, Japiassú [4]: "A forma legítima de interdisciplinaridade procede de uma coerência bastante estreita dos domínios de estudo das disciplinas, havendo certa integração de seus níveis de integração teórica e dos métodos correspondentes" [4].

Diante de tal abordagem, fica evidente a retomada da História da Ciência e Tecnologia ou o próprio desenvolvimento da História da Física, enquanto proposta de formação de um novo campo de estudo, considerando os aspectos relevantes para uma ou outra área, nesse processo um assunto como a Física nuclear seria trabalhado numa visão mais completa, ou seja, determinados pontos que não são abordados exclusivamente pela Física ou História passariam a ser discutidos. Entretanto o que é fomentado pela interdisciplinaridade são os mecanismos de interação e não a criação de novas disciplinas, como ressalta os PCNs,

\begin{abstract}
"Na perspectiva escolar, a interdisciplinaridade não tem a pretensão de criar novas disciplinas ou saberes, mas de utilizar os conhecimentos de várias disciplinas para resolver um problema concreto ou compreender um fenômeno sob diferentes pontos de vista. Em suma, a interdisciplinaridade tem uma função instrumental. Trata-se de recorrer a um saber útil e utilizável para responder às questões e aos problemas sociais contemporâneos"[3]
\end{abstract}

Fica evidente, que a perspectiva interdisciplinar tem caráter investigativo e integrador, possibilitando ao ensino novos caminhos para o seu desenvolvimento. Compreender algo requer mais de um olhar, vai além da fragmentação imposta pela própria conjuntura educacional nos campos das disciplinas e da relação entre os sujeitos do processo, sendo assim a função instrumental que é atribuída à interdisciplinaridade, estabelece a construção de um saber significativo e contextualizado.

Nesse sentido a pesquisa tem como objetivo, analisar aspectos específicos do processo de ensino e aprendizagem, como o grau de conhecimento que os estudantes apresentam da Física nuclear, a forma de abordagem do tema na escola e sua importância. Pontos relevantes que fundamentam os resultados possibilitando uma discussão mais ampla e significativa das etapas do processo educativo e do direcionamento da proposta.

\title{
2. MATERIAL E MÉTODOS
}

A pesquisa foi realizada no Colégio Estadual Anunciada Chaves, sendo esta situada na Av. Juscelino Kubitscheck, Bairro Floresta, do município de Goianésia do Pará. Os Sujeitos da pesquisa foram 30 alunos do $3^{\circ}$ ano do ensino médio, sendo respeitada a disponibilidade e aceitação em participar da pesquisa.

$\mathrm{O}$ estudo foi desenvolvido a partir de uma pesquisa quanti - qualitativa exploratória. A escolha por este tipo de pesquisa constitui - se na mais adequada para identificar o conhecimento dos estudantes em relação ao tema abordado. Para Chizzotti [5], "[...] A pesquisa quanti - qualitativa, pressupõe, na qual o pesquisador descreve, explica, participa, compreende e interpreta" [5].

Desse modo, o método empregado nos ajudou a obter resultados importantes sobre os atores delimitados, permitindo - nos traçar o perfil dos participantes. A coleta de dados ocorreu no dia 27 de junho de 2016, através de um questionário constituído de cinco perguntas de caráter investigativo, a fim de analisar aspectos relevantes a pesquisa considerando perspectivas e possibilidades apresentadas, assim como, incentivar outras pesquisas. Em seguida foi ministrada uma palestra envolvendo o tema em estudo. 


\section{RESULTADOS E DISCUSSÃO}

Apesar do nível de complexidade, a Física nuclear é um tema muito comum e de grande interesse pelos estudantes, fato verificado no referido questionário em que $100 \%$ dos participantes responderam sim quando perguntados, se já tinham ouvido falar do assunto, veja a (figura 1) abaixo. Mas é um assunto que causa medo nas pessoas em geral. "[...] A fobia das pessoas com qualquer coisa nuclear ou radioativa, baseia-se na falta de conhecimento sobre o núcleo e seus processos" [1].

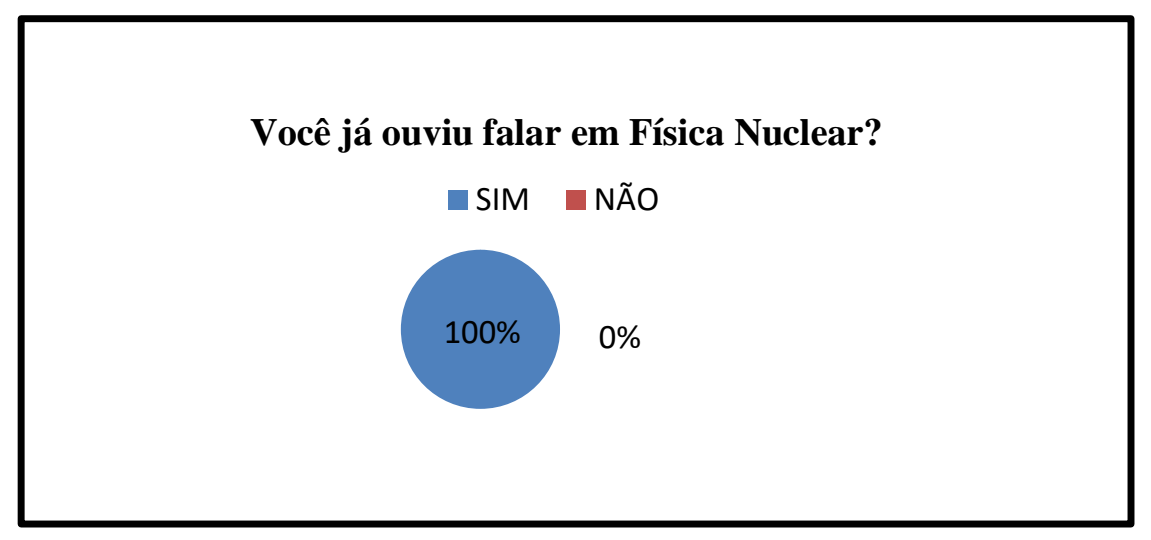

Figura 1: Primeira Pergunta

Temáticas como: armas nucleares, radiação, reatores, aceleradores de partículas, cosmologia etc. Aparecem constantemente em filmes de ficção, séries, documentários, telejornais, tais recursos podem ser usados por professores em vários momentos, dependo da disponibilidade e da necessidade. A pesquisa apontou que cerca de $30 \%$ dos alunos participantes ouviram falar do assunto só na escola, $27 \%$ somente em telejornais, filmes e/ou documentários, $36 \%$ na escola, telejornais, filmes e documentários e 7\% em outros locais, veja a (figura 2) a seguir.

Figura 2: Segunda Pergunta

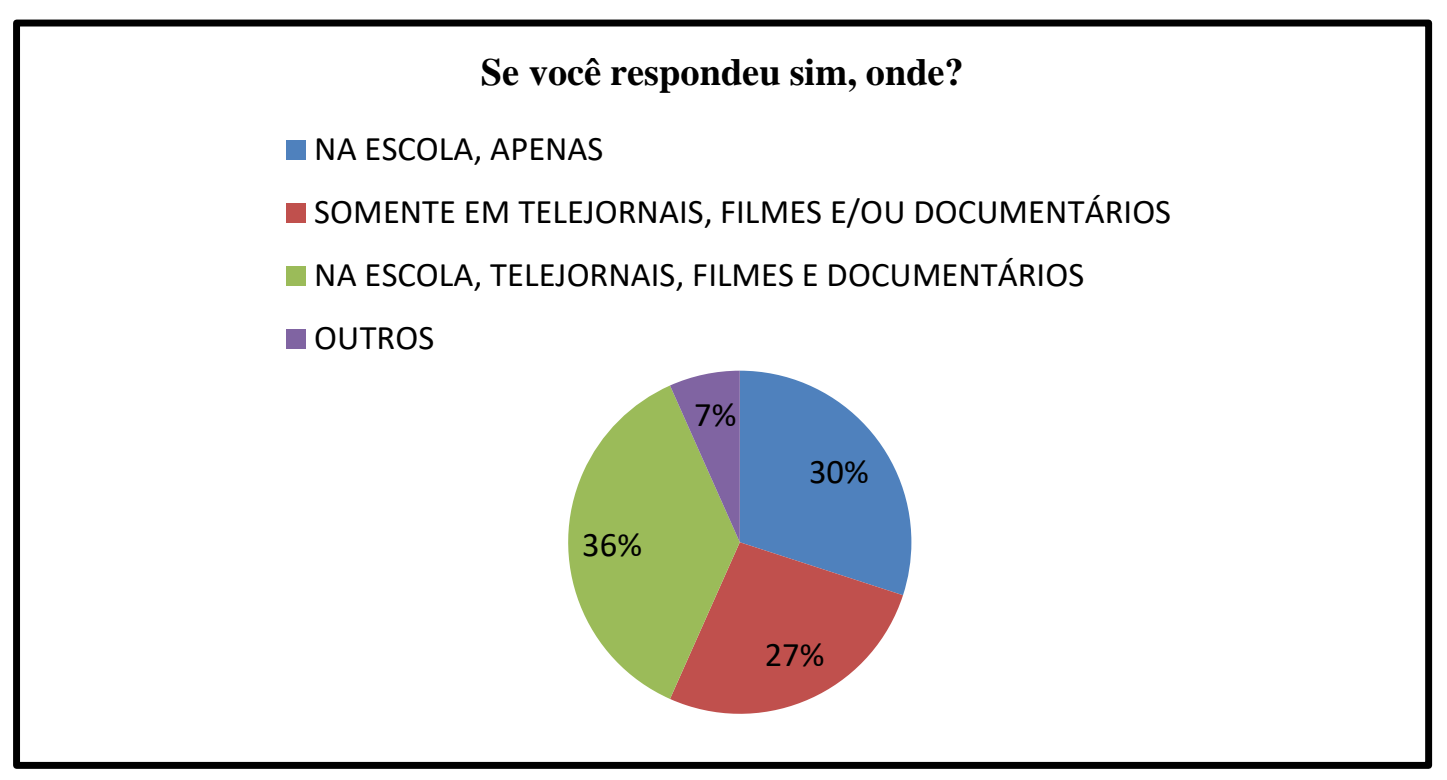

Nesse sentido, é importante que o professor aproveite as informações que os alunos possuem no intuito de discutir e rever conhecimentos relevantes a uma determinada temática. Como, discursa Galembeck [6], “[...] As informações adquiridas associam-se à rede de representações 
conceituais de que dispomos. Assim, nada nos é totalmente novo e aquilo que não entendemos consiste em informações que não conseguimos associar à nossa rede de relações" [6].

No que se refere à forma como a Física nuclear é abordada na escola, 33\% dos entrevistados responderam que é feito exclusivamente a partir da ciência do desenvolvimento das bombas atômicas e armas nucleares, $27 \%$ que o tema é abordado através de suas contribuições nos campos da energia, medicina, agricultura, estudos de radioatividade e partículas subatômicas. E o apanhado mais coerente que considera aspectos da primeira e segunda opção apareceu também com $27 \%$ dos entrevistados enquanto $13 \%$ manifestaram-se no sentido de que o mesmo não é abordado na escola. Como bem mostra a (figura 3) a seguir.

Figura 3: Terceira Pergunta

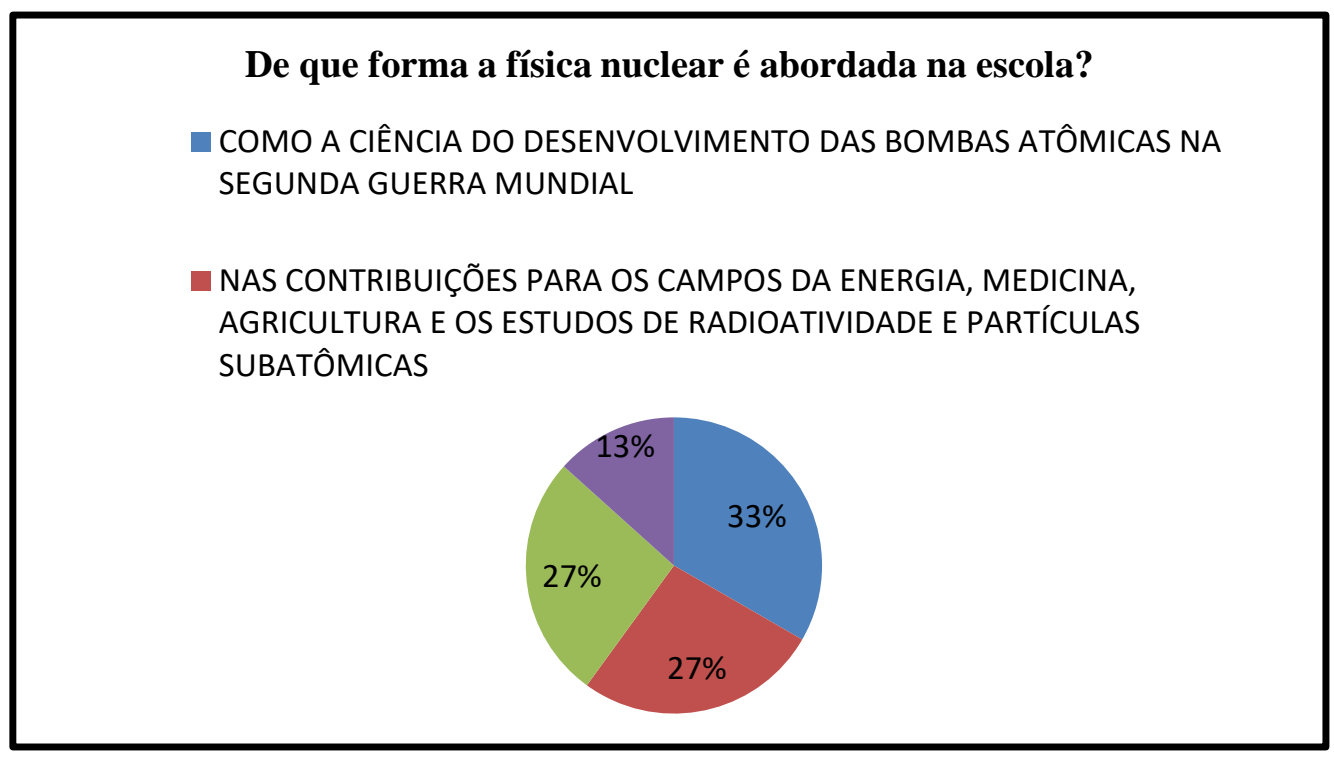

A figura 3 mostra um dos pontos chave da pesquisa, onde aparece de fato à problemática do direcionamento do tema e do embasamento científico e crítico que o aluno deve construir, 33\% dos entrevistados apontam que a realidade em sala está condicionada a uma abordagem histórica superficial faltando elementos Físicos necessários para o desenvolvimento de tal processo. Nesse sentido fundamenta-se a necessidade de interação entre os sujeitos do processo de ensino aprendizagem e as disciplinas na perspectiva da construção de conhecimento.

Em relação à disciplina ou disciplinas que trabalharam a temática em sala, $10 \%$ responderam física, $47 \%$ História, 20\% Física e História e 23\% outras. Veja através da (figura 4) estes resultados obtidos.

Figura 4: Quarta Pergunta

Qual ou quais disciplinas já trabalhou a temática em sala de aula?

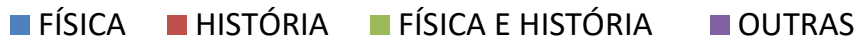

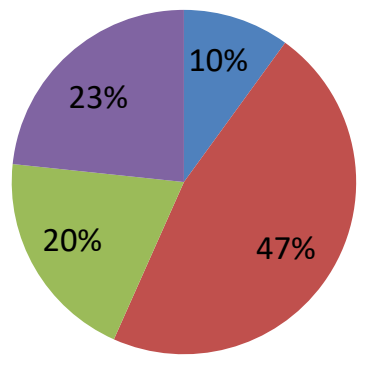


Os resultados obtidos nesse momento da pesquisa revelam inúmeros problemas inerentes do processo que poderiam ser levantados mesmo sem o propósito de analisá-los, como falta de professores, defasagem do currículo, professores despreparados enfim, tudo isso revela a necessidade de articulação, dialogo e integração entre as partes do sistema. Observando a figura 4, apenas $20 \%$ dos alunos responderam ter estudado sobre Física nuclear tanto em aulas de História quanto em Física esse resultado acaba reiterando a preocupação da forma como o assunto é tratado e a reflexão do direcionamento das discussões. Nesse sentido, a interdisciplinaridade, traria contribuições indispensáveis para professores e alunos diante dos problemas a serem enfrentados. Outro fato relevante trata-se da discrepância entre Física e História quando mencionados na pesquisa através da diferença de, cerca de, 37\% no que diz respeito ao tema trabalhado em sala, essa conjuntura possibilita observações inerentes de outros questionamentos da pesquisa.

Quanto à importância do tema para a humanidade, $34 \%$ responderam que por se tratar de estudos exclusivos para o desenvolvimento de armas nucleares, o mesmo não apresenta importância alguma para humanidade, já $43 \%$ dos entrevistados opinaram por sim, tendo em vista sua abrangência em várias áreas de pesquisa como medicina, engenharia e estudos sobre as estrelas e $23 \%$ desconhecem. A (figura 5) abaixo mostrar de forma clara os dados interpretados.

Figura 5: Quinta Pergunta

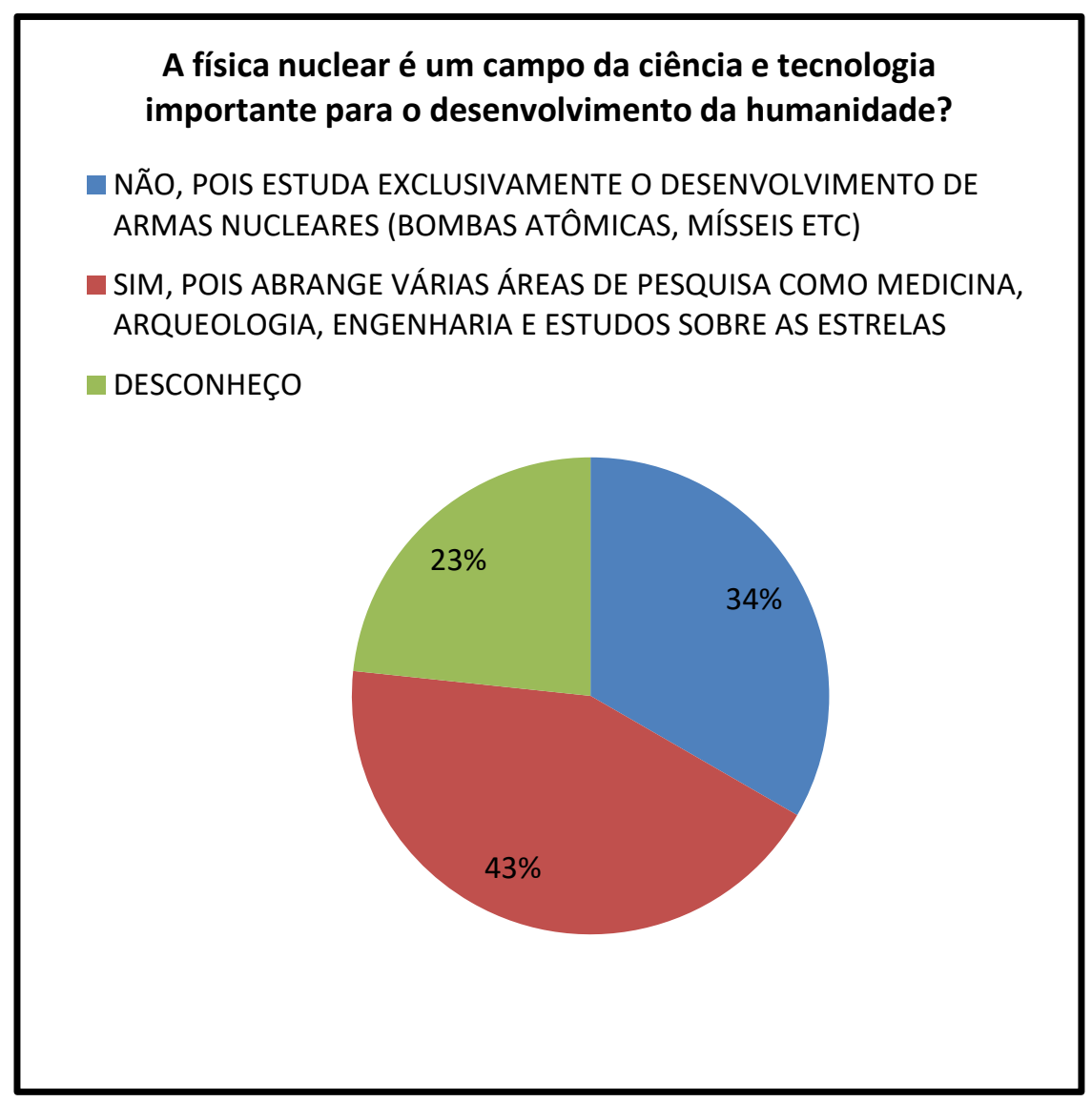

Apesar de $43 \%$ dos entrevistados responderem que, trata-se de um campo de estudos importante para a humanidade, o que fica evidente, são os $34 \%$ de alunos consultados desconhecerem o outro lado da Física nuclear. Identificou-se na contextualização mais um ponto chave da discussão, no que se trata ao desenvolvimento de aulas com temas como o mencionado, permitindo ao professor relacionar os assuntos com o cotidiano e discutir sua importância e significado. Machado [7] enfatiza que: “ [...] Contextuar é uma estratégia fundamental para a construção de significações" [7]. 


\section{CONCLUSÃO}

Através da pesquisa constatou-se que o problema é maior do que imaginava-se, a falta de conhecimento dos alunos acerca do tema reflete a discrepância nos campos das informações e do processo educativo, pois identificou-se que apesar de dispor de vários veículos de comunicação e informação, os estudantes pesquisados, não conseguem construir um saber significativo, articulado aos assuntos da escola, nesse sentido percebe-se que os mesmos não compreendem que o conhecimento é interativo e dinâmico. Da mesma forma verificou-se que o processo de ensino e aprendizagem mantém presente ainda, a fragmentação e o isolamento de disciplinas, o que acaba comprometendo habilidades e competências a serem alcançadas.

Assim, este trabalho busca fomentar a interdisciplinaridade enquanto instrumento educacional necessário à abordagem do tema Física nuclear no ensino médio, considerando fundamental a atribuição de conhecimentos acerca da evolução da Física nuclear, dos usos pacíficos da energia nuclear e outros tópicos que não são discutidos, muito das vezes, por professores de História quando ressaltam o assunto, mas que devem ser abordados em sala dentro das perspectivas apresentadas, com o objetivo de proporcionar ao aluno a construção de um olhar mais contextualizado, intrínseco e coerente do ponto de vista científico.

\section{REFERÊNCIAS BIBLIOGRÁFICAS}

1. Hewitt PG. Fundamentos da Física Conceitual. Porto Alegre: Bookman; 2002.

2. Pinsky CB. Novos temas nas aulas de história. São Paulo: Contexto; 2010.

3. BRASIL. Ministério da Educação. Secretaria de Educação Média e Tecnológica. Parâmetros Curriculares Nacionais: Ensino Médio. Brasília: Ministério da Educação; 2002.

4. Japiassu H. Interdisciplinaridade e patologia do saber. Rio de Janeiro: Imago; 1976.

5. Chizzotti A. Pesquisa em Ciências humanas e Sociais. 7. ed. São Paulo: Cortez; 2005.

6. Galembeck PT. Procedimentos de contextualização: a criação de um espaço comum partilhado pelos interlocutores. Cadernos do CNLF, v. XVIII, p. 111-121, n. 2014.

7. Machado NJ. Educação: projetos e valores. São Paulo: Escrituras; 2000. 